\title{
Immunisation registers in Italy: a patchwork of computerisation
}

V Alfonsi ${ }^{1}$, F D’Ancona (dancona@iss.it) ${ }^{1}$, M C Rota ${ }^{1}$, C Giambi ${ }^{1}$, A Ranghiasci ${ }^{1}$, S Iannazzo ${ }^{2}$, Regional coordinators for infectious diseases and vaccinations ${ }^{3}$

1. Istituto Superiore di Sanità (ISS), National Centre for Epidemiology Surveillance and Health Promotion (CNESPS), Rome, Italy

2. Infectious Diseases Unit, Directorate General of Health Prevention, Ministry of Health, Rome, Italy

3. The regional coordinators are listed at the end of the article

Alfonsi V, D’Ancona F, Rota MC, Giambi C, Ranghiasci A, lannazzo S, Regional coordinators for infectious diseases and vaccinations. Immunisation registers in Italy: a patchwork of computerisation. Euro Surveill. 2012;17(17):pii=20156. Available online: http://www.eurosurveillance.org/ViewArticle.aspx?Articleld=20156

In Italy, the 21 regional health authorities are in charge of organising and implementing their own vaccination strategy, based on the national vaccine plan. Immunisation coverage varies greatly among the regions for certain vaccines. Efforts to increase childhood immunisation coverage have included initiatives to develop and implement computerised immunisation registers in as many regions as possible. We undertook a cross-sectional online survey in July 2011 to provide an updated picture of the use, heterogeneity and main functions of different computerised immunisation registers used in the Italian regions and to understand the flow of information from local health units to the regional authorities and to the Ministry of Health. Comparing current data with those obtained in 2007, a substantial improvement is evident. A total of 15 regions are fully computerised (previously nine), with $83 \%$ of local health units equipped with a computerised register (previously 70\%). Eight of the 15 fully computerised regions use the same software, simplifying data sharing. Only four regions are able to obtain data in real time from local health units. Despite the progress made, the capacity to monitor vaccination coverage and to exchange data appears still limited.

\section{Introduction}

Childhood vaccination services in Italy are usually provided by vaccination centres in local health units (LHUs). To date, there are 157 LHUs in the 21 Italian regions. Since the decentralisation of the Italian national health system in 2001 [1], regional health authorities were charged with organising, coordinating and implementing their vaccination strategy, based on the national vaccine plan [2]. The plan was prepared by the Ministry of Health in collaboration with the National Institute of Health (Istituto Superiore di Sanità, ISS), scientific societies, experts and regional health authorities. In March 2012, a new national vaccine plan for 2012 to 2015 was released [3].
Currently, all the LHUs in Italy estimate vaccine coverage using the administrative method - with the number of vaccinated people as numerator and the local population, obtained from the administrative database or from the health system database, as denominator. The Ministry of Health collects annual data from all the regions on immunisation coverage and on the number of doses administered for most vaccines. The data are collected on paper and the form used is currently under revision to include all the vaccines recommended in the national vaccination schedule.

Even though immunisation coverage in Italy for vaccinations included in the 2005-2007 national vaccination plan is higher than $90 \%$, there are still concerns about the coverage at subnational level (e.g. coverage at age 24 months for diphtheria-tetanus-acellular pertussis-inactivated polio vaccine at the national level is $96 \%$, whereas it ranges from $88 \%$ to $98 \%$ among the regions). Pockets of lower vaccination coverage still exist in certain geographical areas and among hard-toreach population groups, as highlighted by the current resurgence of measles in the country [4]. Furthermore, conjugate pneumococcal, meningococcal $C$ and varicella vaccines are offered by some regions to all children and by others only to people in at-risk groups, leading to variations in coverage rates [5]. However, since the new vaccine schedule adopted in the recently approved national vaccination plan includes human papillomavirus, pneumococcal and meningococcal $C$ vaccines for all newborns and postpones the introduction of mass immunisation against varicella to 2015, it is likely that the differences between regional vaccination coverage will decrease.

Childhood vaccines included in the national vaccination plan are bought by the LHUs and are administered free of charge in the vaccination services. The vaccination services' personnel are in charge of keeping individual records of the administered vaccine doses and 
enter the data into the computerised register, if there is one.

Efforts to increase childhood immunisation efficiency have included initiatives to develop and implement computerised immunisation registers in as many regions as possible. Such registers allows public health personnel to evaluate whether an individual's immunisation history is complete and up to date. This functionality is used to identify individuals who are in need of further immunisation, to generate recall/ reminder notifications for immunisations and to produce immunisation coverage reports, which can be used to evaluate immunisation programmes $[6,7]$. The register should be a confidential, population-based, computerised database that records all immunisation doses administered by participating providers to persons residing within a given geopolitical area [8]. In addition, such registers can facilitate the monitoring of larger areas and evaluation of the impact of the vaccine strategies and also permit a fast and reliable exchange of data.

Implementation of a computerised register was first identified as a priority in Italy in $\mathbf{2 0 0 3}$, in the first national plan for the elimination of measles and congenital rubella [9] and use of such registers has been endorsed in subsequent national plans $[3,10,11]$. Within the framework of a larger project named 'MATTONI', funded by the Italian Ministry of Health [12], an interregional working group in 2007 defined a common minimum set of variables to be included in local computerised registers, to enable the development of a national system capable of aggregating data from all the Italian regions. Furthermore, a recommended information flow from local vaccination centres to the national level was described. The metadata identified included information on a single individual that could facilitate local logistic management and also allow vaccination coverage to be more precisely estimated. It also includes information that allows the vaccination register to be linked with other relevant demographic databases.

At the national level, the aim of the MATTONI project is to feed a centralised information system able to support monitoring of vaccine coverage, evaluation of vaccination strategies and assessment of vaccine effectiveness by collecting aggregated data from the LHUs. This would allow areas with pockets of

\section{FIGURE}

Existence of computerised immunisation registers in Italy, by region, 2007 and 2011

2007

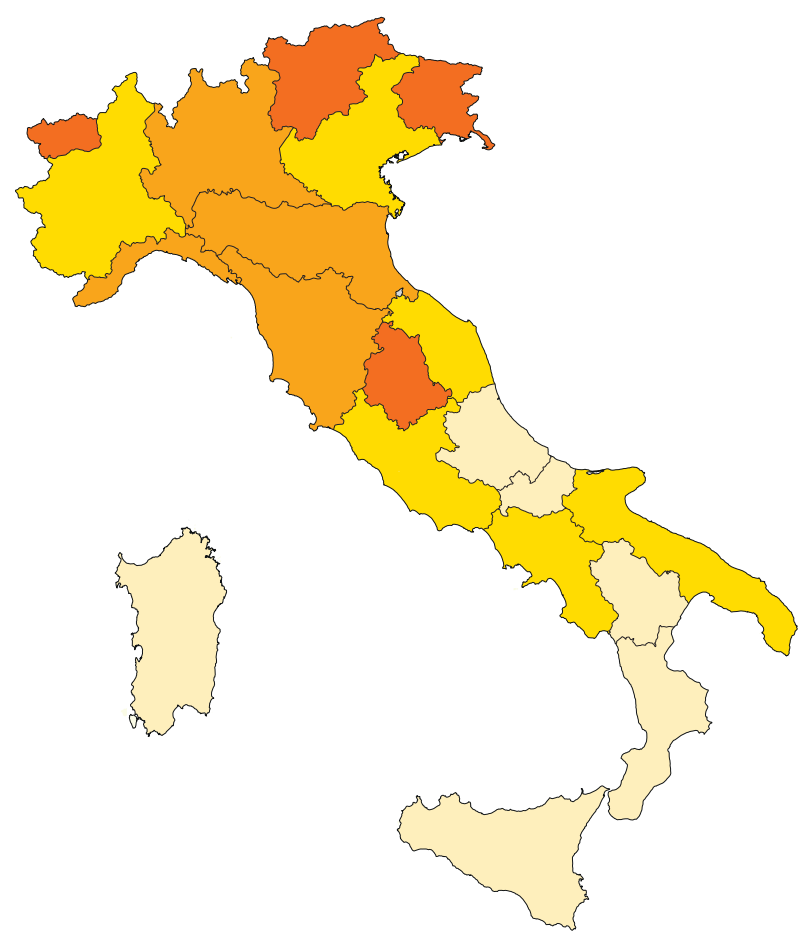

2011

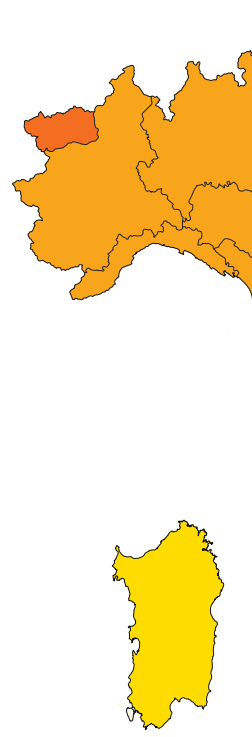

Full computerisation, same software used at LHUs and regional level.

Full computerisation, different software used at LHUs and regional level.

Partial computerisation: computerised register available only in some LHUs. Different software used.

No computerisation: no LHU uses a computerised register.

LHU: local health unit.

Source of 2007 data: [13]. 
susceptible individuals to be identified and would create a link between vaccine coverage and incidence data and identify vaccine failures.

A survey conducted in 2007 to assess the existence of computerised immunisation registers in Italy showed that $70 \%(126 / 180)$ of LHUs were using such registers and that only nine of the 21 regions were fully computerised [13]. The present study aims at providing an updated picture of the use, heterogeneity and main functions of different computerised immunisation registers adopted in the regions and to understand the flow of information from the LHUs to the regional health authorities and to the Ministry of Health.

\section{Methods}

In July 2011, we undertook a cross-sectional survey on the level of computerisation of immunisation registers in the 21 Italian regional health authorities. All regional coordinators for infectious diseases and vaccinations were contacted and asked to fill in a standardised online questionnaire. It included 20 questions about the number of computerised LHUs, use of different or the same software in the LHUs that were computerised, the name and basic characteristics of the software used. In order to explore the flow of information between LHUs and the regions, we also asked about the method and the frequency of data collection (i.e. shared data, transmission of individual or aggregated data). Availability of vaccine coverage for vaccines not included in the national immunisation plan in 2011 (i.e. pneumococcal, meningococcal, varicella and rotavirus vaccines) and for high-risk children was also requested. The questionnaire also asked whether regions with no computerisation or those using more than one such register were planning any changes in the coming years.

Regional coordinators who reported having a single computerised regional register were asked by email or telephone about the characteristics of the software used in the register, confidentiality issues,

TABLE 1

Computerisation of immunisation registers in Italy and data management at regional level, 2011

\begin{tabular}{|c|c|c|c|c|c|}
\hline $\begin{array}{l}\text { Degree of } \\
\text { computerisation }\end{array}$ & $\begin{array}{l}\text { Number } \\
\text { of regions }\end{array}$ & $\begin{array}{l}\text { Proportion of } \\
\text { LHUs using } \\
\text { computerised } \\
\text { register }\end{array}$ & $\begin{array}{l}\text { Proportion of } \\
\text { regions that } \\
\text { automatically } \\
\text { calculate } \\
\text { immunisation } \\
\text { coverage }\end{array}$ & $\begin{array}{l}\text { Frequency of submission } \\
\text { from computerised } \\
\text { LHUs to regional health } \\
\text { authorities }\end{array}$ & $\begin{array}{l}\text { Regions that have access to } \\
\text { computerised individual data }\end{array}$ \\
\hline \multirow{3}{*}{$\begin{array}{l}\text { Full (same software) } \\
\text { Same software used at } \\
\text { LHUs and at regional } \\
\text { level }\end{array}$} & \multirow{3}{*}{8} & \multirow{3}{*}{$21 / 21$} & \multirow{3}{*}{$5 / 8$} & Real time $(n=3)$ & $\begin{array}{l}\text { Direct access to LHU individual } \\
\text { data in real time }(n=3)\end{array}$ \\
\hline & & & & Quarterly $(\mathrm{n}=1)$ & $\begin{array}{l}\text { Access after periodic individual- } \\
\text { data transmission by LHUs }(n=1)\end{array}$ \\
\hline & & & & Every six months $(n=4)$ & No access to individual data $(n=4)$ \\
\hline \multirow{3}{*}{$\begin{array}{l}\text { Full (different software) } \\
\text { Different software used } \\
\text { at LHUs and at regional } \\
\text { level }\end{array}$} & \multirow{3}{*}{7} & \multirow{3}{*}{$84 / 84$} & \multirow{3}{*}{$1 / 7$} & Real time $(n=1)$ & $\begin{array}{l}\text { Direct access to LHU individual } \\
\text { data in real time }(n=1)\end{array}$ \\
\hline & & & & Every six months $(n=3)$ & $\begin{array}{l}\text { Access after periodic individual- } \\
\text { data transmission by LHUs }(n=1)\end{array}$ \\
\hline & & & & Yearly $(n=3)$ & No access to individual data $(n=5)$ \\
\hline \multirow{3}{*}{$\begin{array}{l}\text { Partial } \\
\text { Computerised register } \\
\text { available only in some } \\
\text { LHUs. Different software } \\
\text { used }\end{array}$} & \multirow{3}{*}{5} & \multirow{3}{*}{$25 / 46$} & \multirow{3}{*}{$0 / 5$} & Quarterly $(n=2)$ & \multirow{3}{*}{ No access to individual data $(n=5)$} \\
\hline & & & & Every six months $(n=1)$ & \\
\hline & & & & Yearly $(n=2)$ & \\
\hline $\begin{array}{l}\text { None } \\
\text { No LHU uses a } \\
\text { computerised register }\end{array}$ & 1 & $0 / 6$ & $0 / 1$ & - & - \\
\hline
\end{tabular}


perspectives for future development and any aspects to be improved.

The information obtained was compared with results from the previous survey conducted in 2007 [13].

\section{Results}

Information was collected for all 21 regions, which included a total of 157 LHUs. As shown in the Figure, to date, 15 of the regions and 130 (83\%) of LHUs are fully computerised, five regions are partially computerised and one does not use a computerised register (Figure, Table 1).

Among the 15 fully computerised regions, eight use the same software in all LHUs, while the remaining seven use different software (Table 1). In the five regions not fully computerised, the proportion of LHUs that are computerised ranges from $25 \%$ to $92 \%$ of the LHUs.

LHUs must transmit data to the regional level. Individual data are accessible in only six of the 15 fully computerised regions (Table 1 ); in the remaining nine, individual data are stored in each LHU and only aggregate data on vaccine coverage are sent to the regional level, as in the regions with partial or no computerisation.

Eight of the 21 regions receive data every six months from the LHUs, four receive data in real time, three receive them quarterly and five yearly (Table 1). The capacity of the different systems to manage vaccination coverage data at regional level is very heterogeneous: of the 15 regions that are fully computerised, only six

\section{TABLE 2}

Main features of the immunisation registers at local health unit level in the fully computerised regions using the same software, Italy $(\mathrm{n}=8)$

\begin{tabular}{|l|c|}
\hline Feature & Number of regions \\
\hline $\begin{array}{l}\text { Capacity to list the persons to be } \\
\text { invited for vaccination }\end{array}$ & 8 \\
\hline $\begin{array}{l}\text { Calculation of vaccination coverage } \\
\text { for risk groups }\end{array}$ & 8 \\
\hline $\begin{array}{l}\text { Printing of invitation letters } \\
\text { Managing vaccination appointments }\end{array}$ & 7 \\
\hline $\begin{array}{l}\text { Collecting information on reason for } \\
\text { missed vaccinations }\end{array}$ & 6 \\
\hline $\begin{array}{l}\text { Managing vaccine storage } \\
\text { high-risk group target }\end{array}$ & 6 \\
\hline Producing a list of vaccination delays & 5 \\
\hline
\end{tabular}

are able to calculate vaccine coverage automatically. Of these six, only three can calculate the coverage using individual data available in real time from the LHUs. From the regional level, vaccination coverage data are forwarded to the Ministry of Health once a year.

The main features of the immunisation registers used in the eight fully computerised regions using the same software are presented in Table 2.

The findings of the survey highlight that for paediatric vaccinations not included in the national vaccination plan in 2011, coverage data for children at risk are available at regional level in eight regions for pneumococcal, in seven for meningococcal $\mathrm{C}$, in six for varicella and in three for rotavirus vaccines.

In some of the fully computerised regions, an evolution of the software is already scheduled; in particular, three regions have planned to shift to a web-based system, which is easier and faster than the current computerised register.

All regions not yet fully or not at all computerised are planning to extend the system to the entire region or implement one in the coming years.

\section{Discussion}

In Italy, estimation of vaccine coverage and assessment of vaccination status are always based on individual records for each vaccinated child. There is a large variability in the type of registers used (paper or electronic) but basic information, such as date of vaccination, number of dose, brand and vaccine lot, is always collected. The quality of collected data is good and comparable with those provided by a national cluster sampling survey performed every five years to estimate vaccination coverage with an alternative method [14]. There is, however, considerable variability in the methods used to manage the list of children to call for vaccination, the kind of call (i.e. active versus passive) and in the ability to calculate the vaccine coverage. Extensive use of computerised immunisation registers could help to increase vaccination coverage, but because of the decentralisation of the Italian health system, a single national immunisation register seems to be difficult to realise. This situation appears to be common in Europe: a survey conducted by the Vaccine European New Integrated Collaboration Effort (VENICE ) network in 2007 found that only four countries in Europe have a national computerised immunisation register [15] and many countries, as in Italy, have regional systems. A new survey conducted by VENICE in 2011 showed that five countries have a national register and six have subnational ones [16].

As Italy has a fragmented health system, it seems reasonable that all the existing computerised immunisation registers in the regions could adopt the common minimum dataset proposed by the MATTONI project [12]. These metadata include demographic information 
on the individuals, history of all the administered vaccines (who administered them, when, what and where) and information about non- administration of scheduled vaccinations (including the reasons). All this information should allow a better management of the vaccine centre's activities and a faster calculation of vaccine coverage. Furthermore, using the same metadata, individual-based data exchange among LHUs and regional and national authorities should be facilitated.

A great heterogeneity among regions about health matters has emerged in Italy, sometimes with differences even within the same region [17]. An optimal situation is present only in four regions (with a population equal to $18 \%$ of the total Italian population), where individual data on vaccination history collected at LHUs is shared in real time with the regional level. However, comparing the findings of our survey with those obtained in 2007 , it is evident that there has been some improvement. Currently, of the 15 fully computerised regions, eight use the same software in all their LHUs. These regions are relatively small (all but one have fewer than $1,500,000$ inhabitants): it may be that in small regions (with therefore a small number of LHUs), it is easier to reach a consensus on a common tool.

Although the percentage of LHUs with computerised immunisation registers increased from $70 \%$ in 2007 to $83 \%$ in 2011 , there are still important geographical differences and some regions have not yet covered all their territory. Only one region, in the south, does not yet have any of its LHUs equipped with a computerised register. Moreover, there is considerable difficulty in guaranteeing the transmission of individual data from local to regional level, as only six regions have access to individual vaccination histories.

All the regions with a unique immunisation register that covers all their LHUs agreed that the most important advantages of the register are the simplification of the management of the vaccination centres and the timely availability of coverage data. However, the capabilities of the systems adopted can still be improved - such as the management of the appointments, collection of information on the reasons for missed vaccinations, management of vaccine storage, calculation of vaccine coverage for specific target groups or birth cohorts, management of adverse events, recording linkages between the vaccine register and notification database of communicable diseases and transmission of data to the regional level - are all powerful tools of computerised immunisation register but are not present in all the registers in the eight fully computerised regions that have the same software (Table 2 ).

Increasing the current frequency of annual vaccination coverage assessment seems currently not feasible: data on the vaccination coverage for HPV is collected by the National Institute of Health every six months and it is perceived as an excessive workload in some regions (data not shown). Although there are difficulties at regional level, there are some improvements that should be introduced at national level: aggregated coverage data for recently introduced vaccines are still not routinely collected and there is still no technical document that describes how to send electronic vaccine coverage data from the regions to the Ministry of Health.

In conclusion, this study shows progress has been made towards a more extensive use of computerised immunisation registers in Italy. The adoption of such registers all over the country should improve the management of the vaccination services and the control, at local level, of vaccine-preventable disease. Notwithstanding, the patchy situation in the Italian LHUs, in terms of systems adopted, even within the same region, does not allow an easy transmission of data from the periphery to the centre. The existence of metadata recommended by the MATTONI project is not enough because many regions still do not have access to the individual records present in the LHUs. Furthermore, the Ministry of Health does not require the aggregated data to be sent electronically.

A reasonable objective for the next three years is to have vaccine coverage data at national level for all vaccinations using exclusively electronic data management and transmission from each level (from LHUs to regional health authorities and from there to the Ministry of Health). This will provide more complete and timely data that can be used for monitoring the national vaccination strategies. A flexible and standardised data format should be decided upon for exchange of data among different systems. Furthermore, the new paper form prepared by the Ministry of Health for the collection of regional data should be substituted by a web-based version, in line with the pilot experience of the European Centre for Disease Prevention and Control (ECDC) in collecting vaccine coverage data from European Union Member States at subnational level. In this pilot experience, data entry or file transmission are accepted [18].

Finally, more effort should be made to calculate vaccine coverage for specific target populations (i.e. risk groups or health professionals), as is done for influenza vaccination in Italy and in many other European countries [19]. The new Italian national vaccination plan - with the specific objective of a countrywide diffusion of computerised immunisation registers and a new vaccination schedule for all the diseases common to all the regions - should accelerate the process of computerisation. This should make it easier to identify and actively call unvaccinated children, thus leading to a better control of vaccine-preventable diseases at local level and a better planning of resources and strategies at regional and national level. 


\section{Regional coordinators for infectious diseases and vaccinations}

Abruzzo: Rossana Cassiani; Apulia: Rosa Prato; Aosta Valley : Luigi Sudano; Basilicata: Francesco Locuratolo; Autonomous province of Bolzano: Michele Dagostin; Calabria: Antonio Zaccone; Campania: Renato Pizzuti; Emilia-Romagna: Alba Carola Finarelli, Maria Grazia Pascucci; Friuli Venezia Giulia: Tolinda Gallo; Lazio: Fabrizio Perrelli; Liguria: Roberto Carloni; Lombardy: Maria Gramegna; Marche: Giuliano Tagliavento, Daniel Fiacchini; Molise: Lina D’Alò, Carmen Montanaro; Piedmont: Lorenza Ferrara; Sardinia: Rita Masala, Annamaria Vecchi; Sicily: Mario Palermo; Tuscany: Emanuela Balocchini; Autonomous province of Trento: Valter Carraro; Umbria: Anna Tosti; Veneto: Francesca Russo.

\section{References}

1. Italian Parliament. Legge costituzionale 18 ottobre 2001, n. 3 Modifiche al titolo V della parte seconda della Costituzione. [Law 18 October 2011, n. 3. Modifications of $\mathrm{V}$ title of the second part of National Constitution]. Gazzetta Ufficiale. n. 248. 24 Oct 2001. Italian. Available from: http://www. parlamento.it/parlam/leggi/01003lc.htm

2. Presidency of the Council. State-Regions Conference. Intesa Stato-Regioni. Piano Nazionale Vaccini 2005-2007. [StateRegions Agreement. National Immunization Plan 2005-2007]. Gazzetta Ufficiale. n. 86. Supplemento Ordinario. $14 \mathrm{Apr}$ 2005. Italian. Available from: http://www.unipa.it/cdl/guriall/ guri2005/apro5/5piano_vaccini.pdf

3. Ministry of Health. Piano Nazionale Prevenzione Vaccinale (PNPV) 2012 - 2014. [ National Immunization Prevention Plan 2012 - 2014]. Gazzetta Ufficiale. n. 60. 12 Mar 2012. Italian. Available from: http://www.salute.gov.it/imgs/C_17_ pubblicazioni_1721_allegato.pdf

4. Filia A, Tavilla A, Bella A, Magurano F, Ansaldi F, Chironna M, et al. Measles in Italy, July 2009 to September 2010. Euro Surveill. 2011;16(29):pii=19925. Available from: http://www. eurosurveillance.org/ViewArticle.aspx?Articleld=19925

5. D’Ancona F, Alfonsi V, Caporali M, Ranghiasci A, Ciofi degli Atti ML. Pneumococcal conjugate, meningococcal $C$ and varicella vaccination in Italy. Euro Surveill. 2007;12(2): $\mathrm{pii}=685$ Available from: http://www.eurosurveillance.org/ViewArticle. aspx?Articleld $=685$

6. Development of community- and state-based immunization registries. CDC response to a report from the National Vaccine Advisory Committee. MMWR Recomm Rep. 2001;50(RR17):1-17.

7. Glazner JE, Beaty BL, Pearson KA, Elaine Lowery N, Berman S. Using an immunization registry: effect on practice costs and time. Ambul Pediatr. 2004;4(1):34-40.

8. Samuels RC, Appel L, Reddy SI, Tilson RS. Improving accuracy in a computerized immunization registry. Ambul Pediatr. 2002;2(3):187-92.

9. Presidency of the Council. State-Regions Conference. Intesa Stato-Regioni. Piano Nazionale per l'Eliminazione del Morbillo e della rosolia congenita 2003-2007. [State-Regions Agreement. National Plan for measles and congenital rubella elimination 2003-2007]. Rome: Presidency of the Council; 13 November 2003. [Accessed 20 Apr 2012]. Italian. Available from: http://www.governo.it/backoffice/allegati/20894-1712. pdf

10. Presidency of the Council. State-Regions Conference. Intesa Stato-Regioni. Il Piano Nazionale della Prevenzione 20052007.] [State-Regions Agreement. National Prevention Plan 2005-2007]. Rome: Presidency of the Council; 2005. [Accessed 20 Apr 2012]. Italian. Available from: http://www. ministerosalute.it/imgs/P 17 1 pnpHome file item Name 2 filePdf.pdf

11. Presidency of the Council. State-Regions Conference. Intesa Stato-Regioni. Piano Nazionale Prevenzione 2010-2012. [StateRegions Agreement. National Prevention Plan 2010-2012]. Rome: Presidency of the Council; 2010. [Accessed 20 Apr 2012] Italian. Available from: http://www.salute.gov.it/imgs/C_17_ pubblicazioni_1383_allegato.pdf

12. Ministry of Health. Progetto Mattoni SSN. Assistenza Sanitaria Collettiva. Contenuti informativi minimi per la rilevazione delle prestazioni di Vaccinazione. Metadato per la rilevazione delle prestazioni [Mattoni SSN Project. Population health assistance. Minimum data set for vaccination activities]. Rome: Ministry of Health; 11 Jul 2007. [Accessed 20 Apr 2012]. Italian. Available from: http://www.nsis.ministerosalute.it/mattoni/ documenti/M15_ASC Vaccinazioni.pdf

13. Alfonsi V, D’Ancona F, Ciofi degli Atti ML; Gruppo dei Referenti Regionali per le Malattie Infettive. [Survey on computerized immunization registries in Italy]. Ann Ig. 2008;20(2):105-11. Italian.

14. ICONA Working Group. ICONA 2008: Indagine di COpertura vaccinale NAzionale nei bambini e negli adolescenti. [ICONA 2008: national vaccination coverage survey among children and adolescents]. Rome: Istituto Superiore Di Sanità; 2009. Rapporti ISTISAN 09/29. [Accessed 20 Apr 2012]. Italian. Available from: http://www.iss.it/binary/publ/cont/09_29_ web.pdf

15. Vaccine European New Integrated Collaboration Effort (VENICE) Network. Report on vaccination coverage assessment in Europe. VENICE. December 2007. VENICE work package no. 3. VENICE; 2009. Available from: http://venice.cineca.org/ Final_Report_I_WP3.pdf

16. Vaccine European New Integrated Collaboration Effort (VENICE) Network. Vaccination coverage assessment in EU/EEA, 2011. VENICE II Consortium. August 2011DMarch 2012. Developed by work package no. 4. VENICE; 2012. [Accessed 20 Apr 2012]. Available from: http://venice.cineca.org/Final_Vaccination Coverage_Assesment_Survey_2011_1.pdf

17. Alfonsi V, D’Ancona F, Giambi C, Nacca G, Rota MC; Regional Coordinators for Infectious Diseases and Vaccinations. Current immunization policies for pneumococcal, meningococcal $C$, varicella and rotavirus vaccinations in Italy. Health Polic. 2011; 103(2-3):176-83.

18. D’Ancona F, Giambi C, Cotter S, Glissman S, Levy-Bruhl D, Mereckiene J, et al. A new model for vaccination coverage data collection from the European Union Member States: a proposal of the VENICE network. Presentation at the European Scientific Conference on Applied Infectious Disease Epidemiology (ESCAIDE), 6-8 November 2011, Stockholm. [Accessed 20 Apr 2012]. Available from: http://ecdc.europa.eu/en/ESCAIDE/ Materials/Presentations/ESCAIDE2011_Session_11_5 Dancona.pdf

19. Vaccine European New Integrated Collaboration Effort (VENICE) Network. Final report. Seasonal influenza vaccination survey in EU/EEA, influenza season 2009-10. VENICE II Consortium; AprSept 2011. Developed by work package no. 4. VENICE; 2012. [Accessed $20 \mathrm{Apr} 2012$ ]. Available from: http://venice.cineca. org/Final_Seasonal_Influenza_Vaccination_Survey_2010.pdf 